\title{
Sendas do Letramento Literário pela magia do romance: resultados parciais de uma proposta de intervenção
}

\author{
Sendas do Letramento Literário by the magic of the novel: partial results of an \\ intervention proposal
}

\author{
Lucivania Silva Lopes Rios* \\ Universidade Estadual de Feira de Santana \\ Feira de Santana, Bahia, Brasil \\ Antonilma Santos Almeida Castro** \\ Universidade Estadual de Feira de Santana \\ Feira de Santana, Bahia, Brasil \\ Universidade do Estado da Babia \\ Conceição do Coité, Bahia, Brasil
}

\begin{abstract}
Resumo: Neste artigo, apresentamos resultados parciais de uma intervenção aplicada em uma turma de $9^{\circ}$ ano, do Ensino Fundamental, zona rural de Conceição do Coité. A ideia surgiu da inquietação diante da dificuldade dos alunos frente a leitura de textos do gênero romance. Frente a tal contexto, sentiu-se necessidade de elaboração de um trabalho com letramento literário, no desejo de contribuir para a ampliação leitora dos alunos e aproximá-los desse gênero. Para fundamentação teórica do projeto foram feitas várias consultas: Soares (2002), Kleiman (2006) e Roxo (2012) versando sobre os estudos de (multi)letramentos; Jouve (2002), Antunes (2003) e Solé (1998) discutindo a dimensão interacional da leitura; Lajolo (1988) e Cosson (2014) embasando os estudos da literatura; os PCNs (1998), Marcuschi (2008), Dolz e Schneuwly (2004) explorando a perspectiva e aplicação dos gêneros; e Bakhtin (1997), apresentando as classificações e base teórica do romance. A proposta foi organizada em Sequência Didática, norteando o trabalho de leitura do romance $A$ menina que cavava com a caneta, de Sarah Correia, permitindo o diálogo com outras obras. A proposta centra-se na perspectiva intersemiótica, possibilitando o contato com outros gêneros e outras linguagens. Os resultados parciais apontam: a aproximação dos alunos com o romance; o estreitamentos nas relações afetivas; dinâmica nas aulas de Língua portuguesa; e percepção da importância da literatura na vida cotidiana das pessoas. Tendo em vista a função social que tem a leitura literária para a emancipação do ser, considera-se que esta proposta constituise uma importante alternativa para a formação do leitor.
\end{abstract}

Palavras-chaves: Leitura. Leitura literária. Letramento. Gênero romance.

Abstract: In this article, we present partial results of an intervention applied in a class of 9th grade, Elementary School, rural area of Conceição do Coité. The idea arose from the restlessness before the difficulty of the students in the reading novels. Faced with such a context, it was necessary to elaborate a project with literary literacy, goaling to contribute to the student's reading expansion and to bring them closer to this genre. The theoretical basis of the project was the following: Soares (2002), Kleiman (2006) and Roxo (2012) on the (multi) literacy studies; Jouve (2002), Antunes (2003) and Solé (1998) discussing the interactional dimension of reading; Lajolo (1988) and Cosson (2014) supporting the literature studies; the PCNs (1998), Marcuschi (2008), Dolz and Schneuwly (2004) exploring the perspective and application of the genres; and Bakhtin (1997), presenting the classifications and theoretical basis of the novel. The proposal was organized in Didactic Sequence, orienting the projetc of reading the novel The girl that digged with the pen, of Sarah Correia, allowing the dialogue with other works. The proposal focuses on the intersemiotic perspective, enabling contact with other genres and other languages. The partial results indicate: the students' approach to the novel; the narrowing of

\footnotetext{
* Professora da Rede Estadual de Educação da Bahia e possui mestrado em Letras (PROFLETRAS/UEFS). E-mail:

** Doutora em Educação, professora da Universidade Estadual de Feira de Santana e da Universidade do Estado da Bahia. E-mail:
} 
affective relationships; dynamics in Portuguese language classes; and perception of the importance of literature in people's daily lives. Considering the social function that has the literary reading for the emancipation of the being, it is considered that this proposal constitutes an important alternative for the formation of the reader.

Keywords: Reading. Literary reading. Literature. Romance genre.

\section{PALAVRAS INICIAIS}

Muitos são os desafios a serem enfrentados na escola pública e há necessidade de se repensar as estratégias do trabalho das aulas de Língua Portuguesa, no que se refere ao exercício da leitura, sobretudo com a leitura literária. O projeto de intervenção Sendas do Letramento Literário pela magia do romance: uma proposta de intervenção ${ }^{1}$ nasceu de uma inquietação resultante da percepção da fragilidade dos trabalhos com a leitura de romances na sala de aula. Era notório o desinteresse dos alunos quando se apresentava alguma proposta para se fazer a leitura de algum romance: "É uma leitura chata!", "O livro é muito longo!", "São muitas páginas!", "Esse tipo de leitura cansa!”. Essas e outras justificativas eram apresentadas pelos alunos que muitas vezes se negavam em realizar as leitura propostas.

Paradoxalmente, mesmo com essas reações não podemos, categoricamente, afirmar que os nossos alunos não são leitores ou não gostam de ler. É perceptível que, os nossos estudantes, atualmente, estão a todo instante conectados e têm maior contato com textos multisemióticos, privilegiando outros textos em detrimento do romance impresso. E, é bem verdade que por se tratar de uma leitura mais longa, muitos alunos sentem-se desmotivados para a leitura do gênero em questão.

Diante deste contexto, o referido projeto esboça uma proposta de leitura, na perspectiva do letramento literário, com alunos $9^{\circ}$ ano do Ensino Fundamental, do Colégio Estadual Rio Branco, município de Conceição do Coité. Esses alunos possuem entre 13 e 18 anos e são filhos de lavradores e produtores de beiju, como fonte básica de renda, além do Bolsa Família ${ }^{2}$. São de famílias oriundas da zona rural e os estudantes, em sua maioria, não possuem apoio dos pais na realização das tarefas extraclasses, pois muitos pais são analfabetos ou semianalfabetos e talvez, por essa razão, não estimulem exercícios de leitura.

A situação descrita permite inferir que as dificuldade de compreensão leitora desse grupo de alunos advém, em parte, do contexto sócio-histórico cultural. Entendemos que a leitura se constituiu em ato individual, necessitando de uma base cognitiva, mas também é também uma ação social que depende das interações sociais e culturais. Assim teorizam Antunes (2003), Jouve (2002), Solé (1998), Silva (1986), Yunes (2002) e outros estudiosos que tratam da leitura nas suas múltiplas dimensões.

Nessa linha de entendimento do ato de ler, o objetivo desta proposta de intervenção é ampliar a competência leitora dos alunos, por meio da elaboração e aplicação de práticas

\footnotetext{
1 Projeto do Mestrado Profissional em Letras (PROFLETRAS), da Universidade Estadual de Feira de Santana (UEFS).

2 Programa de complementação de renda do Governo Federal.
} 
de leitura a partir da obra $A$ menina que cavava com a caneta, de Sarah Correia (2016). Nossa intenção é fazer com os alunos percebam o texto literário como uma experiência de autorreflexão, reconheçam a função sociocomunicativa do texto literário e vivenciem experiências de letramento literário, contribuindo para a formação de leitores críticos. $\mathrm{O}$ desejo é, sobretudo, que os alunos percebam o texto literário como possibilidade de interação com o mundo, com os diferentes sentidos da vida.

Nessa direção, a realização dessa proposta se justifica a partir da necessidade de um trabalho mais efetivo com o gênero romance na escola, compreendo que esse gênero aponta toda uma contextualidade social e cultural, que envolve o sujeito e suas relações interpessoais nas diferentes esferas sociais nas quais está inserido. No chão desse pensar, consideramos importante que instituições escolares valorizem o trabalho com esse gênero e com a literatura de modo geral, a fim de que se percebam as interações que acontecem na sociedade e também para a reflexão de questões voltadas para a cidadania e humanização do ser (YUNES, 2002). Assim, entendemos que a leitura de um romance pode oferecer ao leitor a oportunidade de refletir aspectos identitários, de reconhecer seu lugar no mundo, de conhecer histórias de outros povos ou de outras épocas, histórias simples (ou não), mas com múltiplos saberes.

No desejo de ampliar essas pautas discursivas, o movimento deste texto segue na direção de trazer, inicialmente, discussão sobre a função da social da leitura e da leitura literária e a apontar o gênero romance como prática de letramento literário na escola. Para, em seguida, trazer o detalhamento da Sequência Didática utilizada na proposta metodológica e alguns resultados parciais do referido projeto de intervenção.

\section{LEITURA E LETRAMENTOS: FUNÇÃO SOCIAL}

Com a proposta de um maior embasamento teórico para a produção deste artigo científico, alguns estudiosos da área de letramento, leitura, leitura literária e romance foram consultados. Soares (2002) e Kleiman (2006) deixam claro que o conceito de letramento surge como uma maneira de pontificar o embate da leitura e da escrita em todas as situações vivenciadas em sociedade, não restringindo apenas ao âmbito escolar. $\mathrm{O}$ letramento tem um vínculo com as práticas sociais que usam a escrita, e consequentemente, a leitura.

O letramento é complexo, envolvendo muito mais do que uma habilidade (ou conjunto de habilidades), ou uma competência do sujeito que lê. Envolve múltiplas capacidades e conhecimentos para mobilizar essas capacidades, muitos dos quais não têm necessariamente relação com a leitura (KLEIMAN, 2006, p. 18).

Kleiman (2006) defende a ideia de que alfabetizar é apenas uma das práticas de letramento, essencialmente escolar, mediada por um professor. O letramento não constitui um método, nem uma habilidade específica, é a imersão do indivíduo nas práticas sociais cotidianas. Alunos do Ensino Fundamental (caso dos sujeitos envolvidos no projeto de intervenção), por exemplo, já conseguem depreender o sentido de um texto. Assim, já possuem um grau de letramento maior do que de uma criança. 
Soares diz que (2002, p. 18, grifo da autora), "Letramento é, pois, o resultado da ação de ensinar ou de aprender a ler e escrever: o estado ou a condição que adquire um grupo social ou um indivíduo como conseqüência de ter-se apropriado da escrita". Nesse contexto, letramento é apropriação da cultura escrita para o desenvolvimento de habilidades de práticas sociais. Práticas que possam contribuir para uma sociedade mais cada vez mais justa e mais humana.

Quaisquer que sejam os significados da palavra "letramentos", devem ser vistos de forma abrangente, pois são interativos, transgridem relações de poder e são híbridos (ROJO, 2012). Os textos e seus sentidos ultrapassam as relações de poder, principalmente no que tange às ferramentas tecnológicas e "violam" os limites das fronteiras de linguagens, mídias e culturas. Outros tempos exigem novas formas letramentos e essas novas formas são chamadas por Rojo (2012) de "multiletramentos". Esse neologismo ${ }^{3}$ foi criado a partir do peso semântico do prefixo "multi", para dar ênfase a variedade de letramentos disponíveis. Esse conceito, atrelado a uma pluralidade de linguagens e de processos semiológicos, coadjuvam com a multiplicidade de processos constitutivos de uma diversidade cultural bem ampla, em virtude da esfera digital e de manifestações plurais, cada vez mais híbridas, seja no cotidiano social, seja no cotidiano da escola.

\section{A LEITURA LITERÁRIA NA ESCOLA}

É certo que a literatura não tem uma função em si mesma, ela é uma arte. Por outro lado, essa arte igualmente (ou não) tem condições de oferecer a oportunidade de transformação do indivíduo. A leitura literária é "uma prática frutuosa da qual o sujeito sai transformado" (JOUVE, 2002, p. 138). E, transformado, o sujeito pode, de alguma forma, cooperar na construção de um mundo melhor. A partir de leituras de Cosson (2014), de Jouve (2002) e de Cândido (2011), percebemos o caráter pedagógico da leitura literária e seu "poder" de utilizar-se da palavra para dar "forma" aos sentimentos, de fazer o sujeito enxergar a vida com outros olhos e de outros ângulos.

A leitura é uma prática constante na vida de todas as pessoas, de igual modo, de todo aluno. É uma ação individual (e simultaneamente social) capaz de provocar impacto no leitor e fazê-lo refletir sobre sua realidade; podendo, portanto, (re)dimensionar o fazer (ou ser) social. O ato de ler compreende um processo multíplice, plural que envolve duas dimensões essenciais: a cognitiva (entendimento do texto), que requer saber mínimo; e, a subjetiva (engajamento afetivo), que suscita determinadas emoções no leitor (JOUVE, 2002). Envolve capacidades diversas de decifrar, pensar, analisar e construir. Quando não é simples decodificação, todo processo de leitura é significativo; pois, é um artifício de inserção do homem na história e uma ferramenta de compreensão da realidade, ocupando, portanto, um papel preponderante na vida do sujeito, por "abrir portas", ampliar horizontes e emancipar o ser. Como a leitura ocorre em todos os segmentos da vida humana, é uma prática de linguagem que afeta processos políticos, ideológicos, sociais,

\footnotetext{
${ }^{3} \mathrm{O}$ termo foi configurado como neologismo até o momento de ser aceito e incorporado pelos falantes do meio acadêmico da área de Educação.
} 
culturais e educacionais. Daí a nossa defesa em acreditar que é importante que o país invista na leitura, na quantidade e na qualidade de seus leitores.

Talvez ainda não tenhamos quantidade e qualidade no que se refere aos leitores no contexto social e sobretudo escolar, pelo fato de como se percebe a leitura e suas múltiplas dimensões. Antunes (2003) faz uma crítica às aulas de Língua Portuguesa que são ministradas na maioria das escolas brasileiras. É comum práticas de leitura tendo como fim uma escrita artificial, aplicações de atividades mecânicas, com memorização de regras ortográficas e classificação de elementos gramaticais, listas de exercícios sem sentido para o aluno, desvinculados de contexto comunicativo. São corriqueiras as atividades de leitura, nas quais as interpretações se restringem a elementos literais e explícitos do texto, atividades estas que não possibilitam "suscitar no aluno a compreensão das múltiplas funções sociais da leitura (muitas vezes, o que se lê na escola não coincide com o que se precisa ler fora dela)" (ANTUNES, 2003, p. 28), ou seja, ainda persistem nas escolas aquelas atividades incapazes de fomentar no estudante a percepção das mais variadas funções sociais e que não despertam motivação, nem prazer ao mesmo. O que se vivencia na ambiência escolar ${ }^{4}$ é muito mais o afastamento do texto literário do que a aproximação afetiva com essa ferramenta de acesso a diferentes mundos, espaços e saberes.

É comum encontrarmos alunos com dificuldades em realizar leituras em consonância com as habilidades esperadas na Matriz de Referência ${ }^{5}$ para a área de Linguagens, no Ensino Fundamental, ou seja, alunos que leiam com proficiência, criticidade, autonomia e autoria nas releituras e não somente alunos que apenas decodifiquem os sinais, quando muito! Para amenizar essas dificuldades, Antunes (2003, p. 33) sugere que os profissionais de educação revejam suas práticas pedagógicas, e para isso é indispensável, sobretudo, que tenham "determinação, vontade, empenho de querer mudar".

Desde a década de 1990, há uma preocupação no Brasil para uma mudança em seu sistema educacional e foi com essa intenção que os PCNs foram elaborados e a Base Nacional Comum Curricular (BNCC) foi, recentemente, aprovada ${ }^{6}$. Esses documentos, consideram a necessidade de construção de matizes nacionais comum ao processo educativo de todas as regiões brasileiras, respeitando as diversidades regionais e culturais, aspectos relevantes para professores e alunos da zona rural de uma cidade do interior da Bahia (região Nordeste), como é o caso dos estudantes do Colégio Estadual Rio Branco. Outro aspecto destacado nos PCNs-LP, é a valorização e necessidade da presença da literatura nas aulas de Língua Portuguesa, considerando que o uso dos textos literários,

\footnotetext{
${ }^{4}$ Embora não se possa deixar de reconhecer de que já existem, em algumas escolas, projetos que focalizam a leitura literária como fruição, deleite e movimento de criticidade, mas infelizmente ainda são ações/projeto pontuais.

${ }^{5}$ As Matrizes de Referência são constituídas por elementos que descrevem habilidades dos educandos e se responsabilizam por avaliar e indicar a construção de escalas de sua proficiência.

${ }^{6}$ A Base Nacional Comum Curricular foi aprovada em 15 de dezembro de 2017 e homologada em 20 de dezembro do mesmo ano, sob algumas críticas de que apresenta uma visão fragmentada do conhecimento e do desenvolvimento humano.
} 
nos diferentes gêneros, dão embasamento para o desenvolvimento do projeto educativo da escola. Destacam ainda que propostas de trabalho de leitura com o texto literário enriquecem a participação do aluno, contribuindo para seu protagonismo no meio escolar.

Oportuno esclarecer que a BNCC, recente documento oficial, traz no seu bojo igual perspectiva, considerando imperativa a presença do texto literário, nos mais diferentes gêneros, tanto no âmbito da escrita, quanto no da oralidade.

É necessário registrarmos que o ensino, especialmente o de Língua Portuguesa com alcance da literatura, objeto complementar de estudo para a referida pesquisa, é de grande importância, visto que é pelo domínio da língua que os estudantes encontram condição fundamental para progressão de outras áreas do conhecimento. Assim, há necessidade de cursos de aperfeiçoamento para professores da área de linguagens, na direção de redimensionarem as ações pedagógicas, para que essas exigências dos PCNs e da BNCC sejam atendidas.

Os PCNs (1998) e a BNCC (2017) formalizam e impulsionam o trabalho docente e fazem da escola um empreendimento dotado de organização. As atividades do professor devem ser claras e objetivas e sua presença deve responder às expectativas dos alunos. Esses parâmetros e diretrizes sugerem que não só o ensino da língua seja inovador, mas também o ensino da literatura. Lajolo (1999) defende a ideia de que a literatura pode fomentar o desejo de rever posturas, estimular diálogos, despertar interesse pelo outro, incentivar a mudança de atitudes, mostrar a beleza das parcerias; enfim, a literatura tem "poder" de humanizar.

A literatura serve tanto para ensinar a ler e a escrever quanto para formar culturalmente o indivíduo. Foi assim com o latim e o grego antigo, cujo ensino se apoiava nos textos da Era Clássica, para o aprendizado dessas línguas de uso restrito e para o conhecimento produzido nelas. Tem sido assim com o ensino da literatura em nossas escolas, que, no ensino fundamental, tem a função de sustentar a formação do leitor (COSSON, 2014, p. 20).

A literatura possibilita, ao aluno, um maior contato com a língua escrita. A leitura da obra literária pode auxiliar a formação cultural do educando, alargar seu repertório linguístico, ampliar seus horizontes e seu modo de ver o mundo, tornando-o um leitor proficiente. Se a leitura literária for bem explorada, pode ainda despertar paixão no aluno e fazê-lo tomar gosto pela literatura, tão relevante para o currículo do Ensino Médio, imprescindível para a fluência leitora do indivíduo e importante para o ser, essencialmente, humano.

Assim, é necessário mudar os rumos do trabalho com a leitura literária na escola. Zilberman (1991) diz que ao professor compete a transformação de sua atuação na sala de aula, pesquisando o ignoto e buscando novas técnicas de trabalho, na tentativa de aprimorar sua prática no trabalho com a leitura literária.

É a recuperação do fundamento metodológico o ponto de partida para que, no ensino, em qualquer área, coincidam os pressupostos da educação e à prática docente. É vital, para a coerência didática, que o professor organize seu trabalho em sala de aula a partir de uma visão geral dos conteúdos de sua área e de suas expectativas em relação ao aluno (ZILBERMAN, 1991, p. 67). 
Cosson (2014) apresenta duas propostas de trabalho para a leitura literária na sala de aula: Sequência Básica, indicada para turmas do Ensino Fundamental; e, Sequência Expandida, mais apropriada para turmas do Ensino Médio. A Sequência Básica apela para que a leitura literária na escola tenha "saber e prazer" (COSSON, 2014, p. 52) e é formada por quatro etapas: Motivação, Introdução, Leitura e Interpretação. Essas etapas legitimam o trabalho com a leitura literária e justificam a escolha do gênero romance, o qual está explicitado a seguir.

\section{GÊNERO ROMANCE COMO PRÁTICA DE LEITURA E LETRAMENTO NA ESCOLA}

O romance é o gênero escolhido para esta pesquisa de intervenção, gênero pelo qual a prática de leitura pode se fortalecer e auxiliar o desenvolvimento de habilidades essenciais na formação do educando. Essa modalidade de narrativa surge como testemunha da queda da Idade Média e desponta com uma "consciência de transformação". Ela mostrava, à época, conflitos individuais e acontecimentos da vida cotidiana opondo-se a concepções medievais, que valorizavam formas fixas ainda presentes nas epopeias.

No Brasil, esse gênero se autoafirmou no século XIX com o advento do Romantismo, por meio dos folhetins, que era o meio pelo qual as narrativas de enredo passional e peripécias de entretenimento eram passadas para o leitor (SCHÜLER, 1989). O romance brasileiro eclodiu depois do processo de independência do país e coube aos romancistas o ensejo de construir sua imagem, por meio deste tipo de narrativa.

O trabalho com romance, na referida proposta, pauta-se nas especificidades do gênero e nas bases teóricas e classificatórias produzidas por Bakhtin (1997) acerca do Romance de formação na história do realismo. A partir da classificação bakhtiniana, os gêneros se subdividem, em primários e secundários e o romance é classificado como gênero secundário. Bonini (2005), segue a classificação bakhtiniana e exemplifica os gêneros primários como aqueles que apresentam enunciação simples, como os diálogos; e, os gêneros secundários, são os textos mais densos, como os romances, que abrangem outros tipos de gêneros.

Nessa linha de entendimento, "os gêneros secundários do discurso - o romance, o teatro, o discurso científico, o discurso ideológico, etc. - aparecem em circunstâncias de uma comunicação cultural, mais complexa e relativamente mais evoluída" (BAKHTIN, 1997, p. 281). Já os gêneros primários são compreendidos como sequências que estruturam os secundários, ou seja, os gêneros textuais mais complexos em que os interlocutores interagem de modo mais indireto.

Esta proposta de intervenção toma o romance como prática para o letramento literário, porque acredita que este gênero pode criar condições para que o estudante compreenda os acontecimentos da vida, construindo e consolidando uma postura crítica. Isso porque se concebe que as práticas de leitura, na instituição escolar, contribuem para formação do educando e para seu engajamento social. 
É relevante evocar que essas práticas precisam ser bem conduzidas e uma proposta metodológica eficiente pode levar o aluno a aguçar sua sensibilidade, suscitar o senso crítico e um desejo de mudança. Acreditamos que Sequência Didática pode ser um exemplo de condução de trabalho com o texto literário, pois ordena ações e norteia o fazer pedagógico. A seguir, as proposições de nossa Sequência Didática.

\section{NA PROPOSTA METODOLÓGICA, A SEQUÊNCIA DIDÁTICA}

Com uma perspectiva interacionista, o intuito da proposta foi possibilitar diálogos entre o gênero romance e outras linguagens de gêneros textuais heterogêneos, bem como favorecer o entendimento dos textos e contribuir para a competência leitora do educando. Nessa direção, sugerimos para esta proposta de intervenção, uma prática de leitura diferenciada com o gênero romance, proporcionando um contato mais duradouro com o texto. O trabalho foi centrado na obra $A$ menina que cavava com a caneta, de Sarah Correia, estabelecendo diálogo com a obra Capitães da Areia ${ }^{7}$, de Jorge Amado. A ideia foi abrir espaço de confluência entre aluno/autora/obra literária, tornando significativa a discussão do romance (e de outras obras), a partir de perspectivas metodológicas apresentadas por Cosson (2014, p. 46)

É necessário que sejam sistematizados em um todo que permite ao professor e ao aluno fazer da leitura literária uma prática significativa para eles e para a comunidade em que estão inseridos, uma prática que tenha como sustentação a própria força da literatura, sua capacidade de nos ajudar a dizer o mundo e a nos dizer a nós mesmos.

Cosson (2014) propõe, como já foi dito, a Sequência Básica, na qual se tenta fazer da leitura literária uma prática significativa para os alunos. Ela é apropriada para o Ensino Fundamental e é composta das seguintes etapas: Motivação, Introdução, Leitura e Interpretação. Essa sequência foi adotada como base da proposta de intervenção, a qual foi estruturada em função de uma melhor condução sistemática do trabalho, já que se configura em uma estratégia que, de forma planejada, segue uma ordem linear e concatenada de atividades. Essa sequência foi inspirada no modelo proposto por Dolz e Schneuwly (2004) para o trabalho com gêneros textuais, mas há, porém, algumas adaptações, já que o foco do trabalho é a leitura, e não produção de textos ${ }^{8}$.

Pertinente destacar que no esquema de Sequência Didática proposto por Dolz e Schneuwly (2004), inclui: apresentação da situação e produção inicial, três módulos e produção final. No caso desta proposta de intervenção, a sequência sofreu uma adaptação para melhor se adequar ao trabalho com romance. A Sequência Didática está organizada

\footnotetext{
${ }^{7}$ Os alunos terão contato com a obra Capitães da Areia por meio da exibição do filme e pela leitura de alguns capítulos do romance, os quais foram relevantes para estabelecer diálogos a respeito de identidade, relações interpessoais e espaço de origem. A obra foi escolhida por ser citada no romance $A$ menina que cavava com a caneta.

${ }^{8}$ Os alunos são motivados à produção de fanfics (textos escritos por fãs), mas não há trabalho sistemático com reescrita de textos.
} 
em cinco etapas sistematizadas, sendo que a fase intermediária é subdividida em módulos, como se vê na figura 01 .

Figura 01: Esquema da Sequência Didática

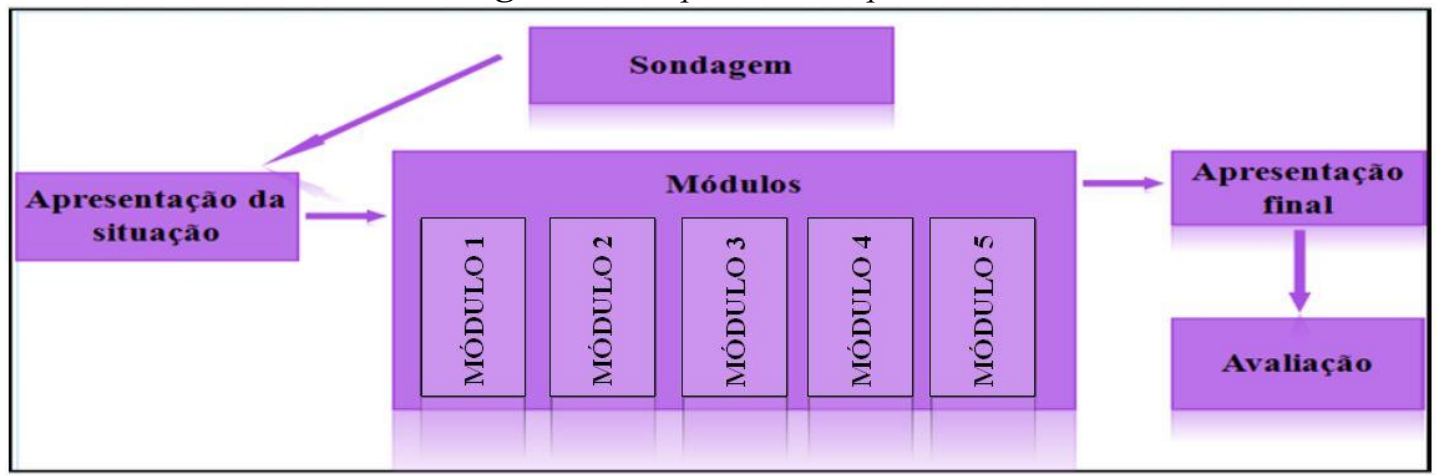

Fonte: Acervo da pesquisadora/ 2018.

Essas etapas ordenam o trabalho:

- Sondagem - momento de descoberta dos conhecimentos prévios do aluno acerca do que já sabe sobre o gênero romance e o nível de interesse por leitura desse tipo;

- Apresentação da situação - exposição da proposta de intervenção e motivação para a leitura do romance, inclusive com um vídeo da autora do romance, motivando os alunos para a leitura;

- Módulos - trabalho sistematizado em categorias temáticas com foco nas características do gênero, aspectos textuais e, principalmente, na leitura dos capítulos do romance e de outros textos de gêneros distintos; além de interpretação e produção de fanfics ${ }^{9}$.

- Apresentação final - culminância em formato de café literário para apresentação de alguns textos produzidos nas aulas e reencontro ${ }^{10} \mathrm{com}$ a autora para uma palestra;

- Avaliação - momento de julgamento do trabalho como um todo.

Válido esclarecer que a estrutura de base da Sequência Didática que norteou esta proposta de intervenção, conjuga o método apresentado no esquema proposto por Dolz e Schneuwly (2004) e as ideias metodológicas da Sequência Básica de Cosson (2014). Esta última se aplica melhor ao projeto de intervenção, por não haver foco na questão da escrita e reescrita de textos. É sustentada nos meandros da motivação, introdução, leitura e interpretação de textos, como mostra o esquema presente na figura 02.

\footnotetext{
${ }^{9}$ Os alunos são incentivados a criar um fandom (espécie de fã clube) para escrever as fanfics (textos escritos por fãs), as quais podem servir para exploração da criatividade e para a expressão dos sentimentos, ideias e emoções dos leitores, a partir das obras lidas.

${ }^{10}$ É bom registrar que é parte integrante do último módulo, uma excursão para a cidade de Monte Santo, cidade onde mora a autora, para um contato com a mesma e para conhecer o espaço que lhe motivou a escrever o cenário da obra.
} 


\section{das Letras}

Figura 02: Esquema da Sequência Didática

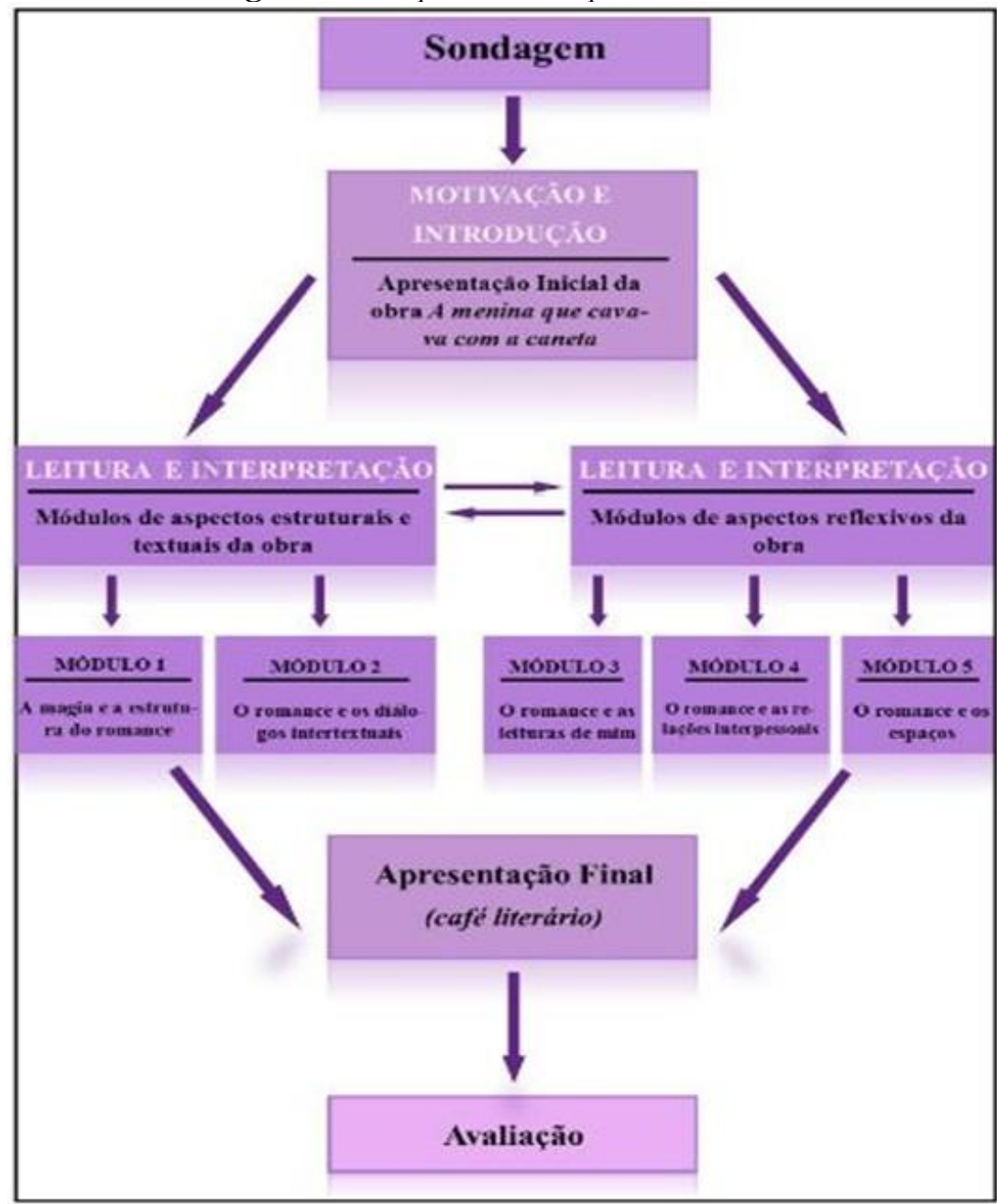

Fonte: Acervo da pesquisadora, elaborado a partir da leitura de Cosson (2014).

Na etapa Motivação, estimula-se a leitura de cada capítulo com dinâmicas de interação, a vivência da Tempestade de ideias, na qual acontece o levantamento das hipóteses dos alunos. Na Introdução, o livro é apresentado, folheado e seus elementos estudados e a apresentação da obra feita pela autora, por meio da exibição de um vídeo. A etapa da Leitura é iniciada na sala, sendo interrompida em um momento empolgante da narrativa. Os alunos dão continuidade em casa, com intervalos entre um capítulo e outro para a etapa da Interpretação, a qual acontece na sala, por meio de discussões nas rodas de conversa, atividades variadas (módulo didático) e análises de trechos do romance e de outros textos (de outros gêneros), que apoiam a concretização do trabalho proposto.

Entre um módulo e outro, a leitura do romance é mediada por intervalos, como propõe Cosson, "durante esse tempo, cabe ao professor convidar os alunos a apresentar 
os resultados de sua leitura no que chamamos de intervalos" (COSSON, 2014, p. 62). Então, a leitura é feita por capítulos constituindo o que o autor chama de intervalos de leitura. Esses interstícios são fundamentais para a concretização do letramento literário, pois funcionam como um diagnóstico para a proposta apresentada e se configuram com momentos de reflexão e atividades específicas referentes aos capítulos lidos e a outros textos que dialogam com as temáticas apresentadas pelo romance.

No caso do romance $A$ menina que cavava com a caneta, de Sarah Correia, há sugestão de cinco intervalos, pois a obra é dividida em 6 capítulos. "Em muitos casos, a observação de dificuldades específicas enfrentadas por um aluno no intervalo é o início de uma intervenção eficiente na formação de leitor daquele aluno" (COSSON, 2014, p. 64).

Nesta proposta de intervenção, a Sequência Básica está centrada em um trabalho que concebe a leitura literária como um produto da interação entre autor/texto/leitor. O texto do romance se dá com trabalho de partes para se chegar ao todo, a fim de que a leitura do texto possa ser feita na íntegra, diferente de como aparece em materiais, manuais ou livros didáticos, cujas fragmentações e/ou adaptações de textos não abrangem a totalidade da obra e não caracterizam um letramento literário eficiente.

No decorrer do percurso, há a intenção é de que haja diálogos intertextuais entre A menina que cavava com a caneta e Capitães da areia, com identificação de trechos da obra, discussões nas rodas de conversa sobre a identidade dos meninos (personagens de Jorge Amado) e de Alice (de Sarah Correia). E ainda, comparação das relações interpessoais e do espaço escolhido como cenário em ambas as obras. Esses diálogos, as abordagens de cunho social e dos temas propostos poderão aparecer nas produções escritas dos alunos (fanfics).

É pertinente destacar o intento de que os alunos produzam fanfics, as quais serão divulgadas em plataformas digitais, como em um site específico para fanfics ${ }^{11}$ e em uma Fanpage (página do Facebook), mostrando criatividade, reflexões, aprendizagens e sensações sentidas por meio da(s) leitura(s). Ainda há o propósito de que os alunos escrevam biografia da autora, sinopses e resenhas da obra. No final do processo, o romance é lido e compreendido em sua totalidade; e os alunos apresentam o resultado de suas leituras e das atividades desenvolvidas para a comunidade escolar e para os pais, em um café literário.

É relevante deixar claro que o projeto de intervenção foi submetido ao Conselho de Ética e Pesquisa (CEP), sob o CAAE n 79264117.8.0000.0053 e aprovado conforme o parecer consubstanciado de $\mathrm{n}^{\circ} 2.459 .863$.

\section{RESULTADOS PARCIAIS DA INTERVENÇÃO}

A turma escolhida para a aplicação da Sequência Didática era composta de alunos que diziam não gostar de ler. Inclusive, esse foi o motivo pelo qual a turma foi escolhida. Era uma turma de dezenove alunos no processo inicial. Logo na segunda semana da execução do projeto, um dos alunos, já maior de idade, foi transferido para a turma de

${ }^{11}$ Nyah Fanfiction: https://fanfiction.com.br/ 


\section{Revista

Educação de Jovens e Adultos (EJA). E depois da primeira unidade, no meio do processo, mais dois alunos (irmãos) pediram transferência, porque os familiares foram morar em outro município e uma outra aluna se afastou para acompanhar o cônjuge. Houve assim uma baixa do contingente, mas isso não reduziu a expectativa das proposições inicias

A turma possuía cinco alunos repetentes no $9^{\circ}$ ano e três que repetiram o $8^{\circ}$ ano. Mais de 30\% da turma apresenta distorção idade/série. Uma quantidade significativa de alunos dessa turma resistia a qualquer atividade de leitura, sendo ou não de texto literário, fato que foi confirmado pela atividade diagnóstica.

Figura 03: Gráfico correspondente à questão 01 da sondagem

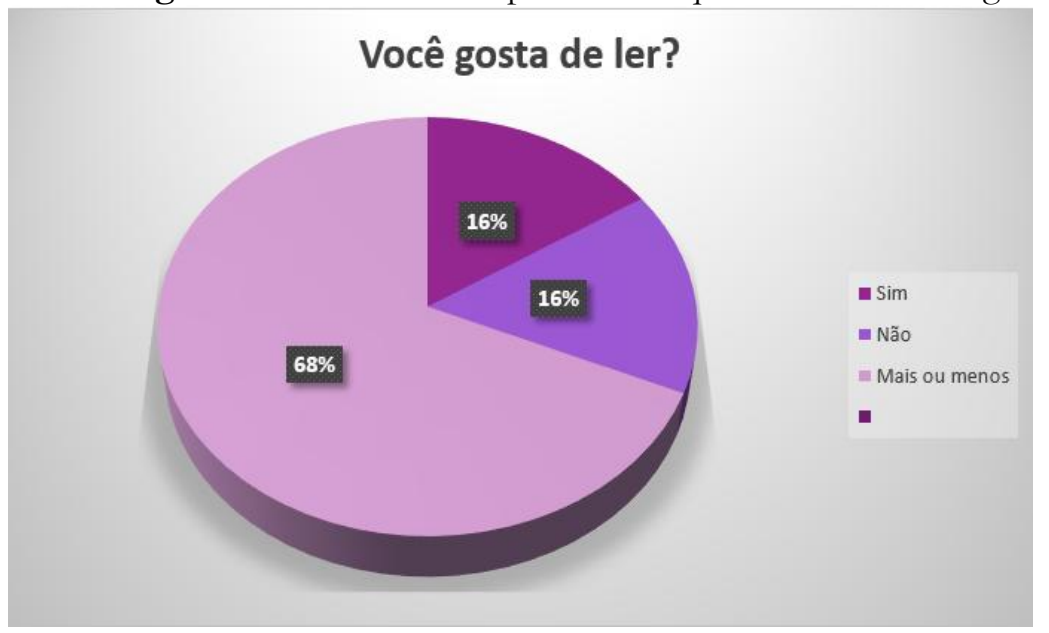

Fonte: Acervo da pesquisadora.

Figura 04: Gráfico correspondente à questão 10 da sondagem

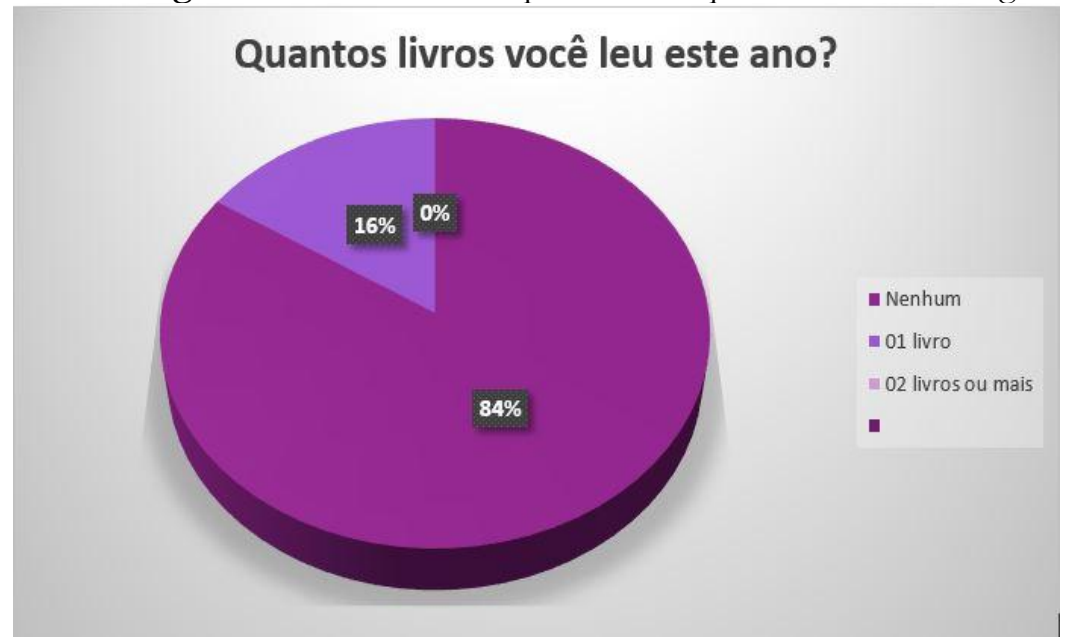

Fonte: Acervo da pesquisadora.

Três dos dezenove alunos, afirmaram que gostavam de ler. E mesmo que $68 \%$ dos alunos tenham respondido "Mais ou menos" para a pergunta "Você gosta de ler?", 
pode-se verificar no gráfico correspondente à questão dez da sondagem, que a resposta dada não tem fundamento, já 84\% dos estudantes afirmaram que ainda não tinham lido nenhum livro no ano, até o início da intervenção. Isso dá um demonstrativo da falta de gosto e de interesse pela leitura, de um modo especial, a leitura de romance.

Diante do exposto, mesmo que de forma parcial, podemos avaliar a proposta de intervenção como produtiva, pois com exceção de um dos estudantes, todos os outros conseguiram fazer a leitura e $84 \%{ }^{12}$ dos alunos fizeram-na com agilidade e com entusiasmo. Isso pode ser constatado por observações feitas nas rodas de conversa e em outros momentos das aulas. Comentários como "Não consigo parar de ler o livro", "Quando terminar o trabalho com esse livro, pode fazer com outro?", "Esse foi o melhor livro que eu já li” eram comuns nas aulas.

Esta foi uma oportunidade para muitos alunos, os quais não se interessam em buscar um texto para ler, inclusive o texto do romance, dada a extensão da leitura. Então, proporcionar esse contato com o romance, por si só, em uma turma que não estava habituada a trabalhar com o gênero, já é algo positivo. Isso nos faz refletir sobre a responsabilidade do professor em propiciar esse contato entre texto e leitor na escola, já que fora dela, esse contato é mais dificultoso.

O projeto de leitura foi inédito, pois os alunos ainda não tinham participado de uma experiência de leitura com esse formato, com intervalos de leitura e com atividades dinâmicas e diferenciadas dentro e fora da sala de aula. De acordo com a atividade diagnóstica, para quatro dos dezoito alunos essa foi a primeira experiência de ler um livro na íntegra, como se verifica no gráfico.

Figura 05: Gráfico correspondente à questão 13 da sondagem

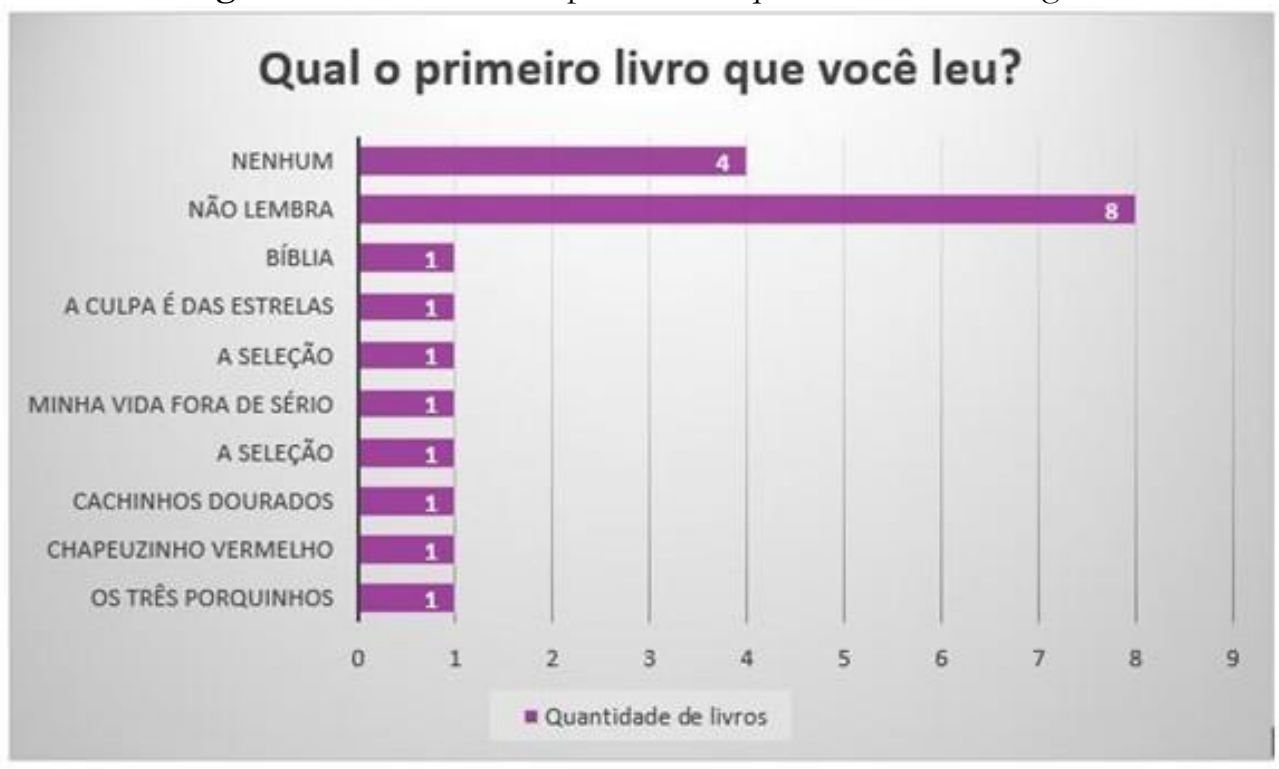

Fonte: Acervo da pesquisadora.

\footnotetext{
${ }^{12}$ Dado obtido por meio da avaliação das etapas da proposta de intervenção.
} 


\section{das Letras}

Houve um entusiasmo muito grande da turma para a leitura do romance. Grande parte dela adiantou a leitura que estava sendo feita por capítulos, com pausas configuradas em intervalos de leituras. O gráfico a seguir revela o acompanhamento da leitura depois da solicitação para leitura do capítulo três. 43\% dos alunos estavam no capítulo correspondente e outros $43 \%$ já estavam adiantados; portanto, menos de 15\% dos alunos estavam com atraso na leitura.

Figura 06: Gráfico representativo do andamento da leitura no $3^{\circ}$ módulo do projeto

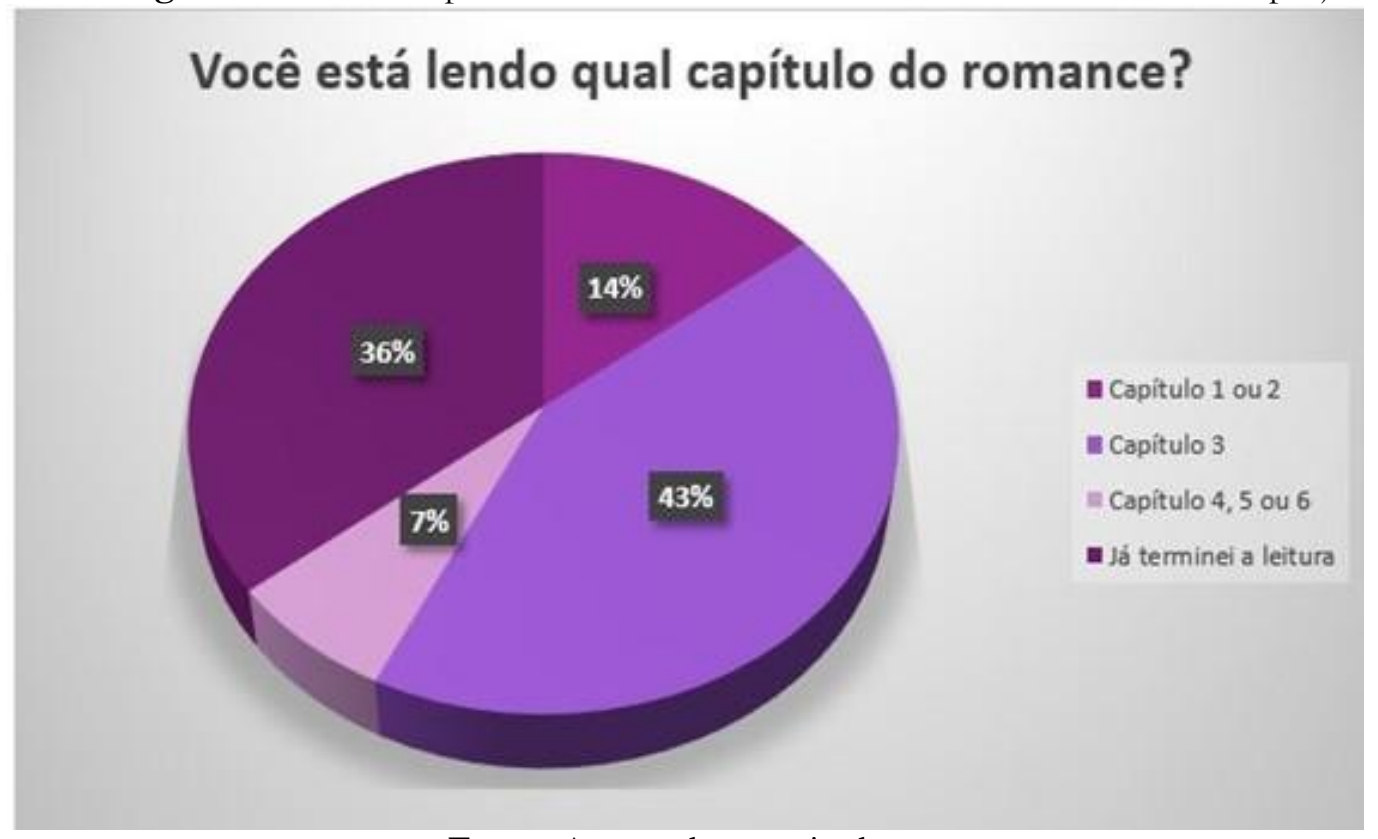

Fonte: Acervo da pesquisadora.

A utilização de diferentes espaços para leitura e para discussão dos capítulos (roda de conversa) foi muito positiva. Foi possível perceber que depois que houve uma arrumação diferenciada na biblioteca, com almofadas dispostas e com melhor aproveitamento do espaço, houve maior interesse dos alunos em frequentá-la. Algumas vezes, a roda de conversa era feita no pátio da escola ou debaixo de uma árvore com os alunos sentados em círculo. 


\section{das Letras}

Figura 7: Imagem de uma roda de conversa

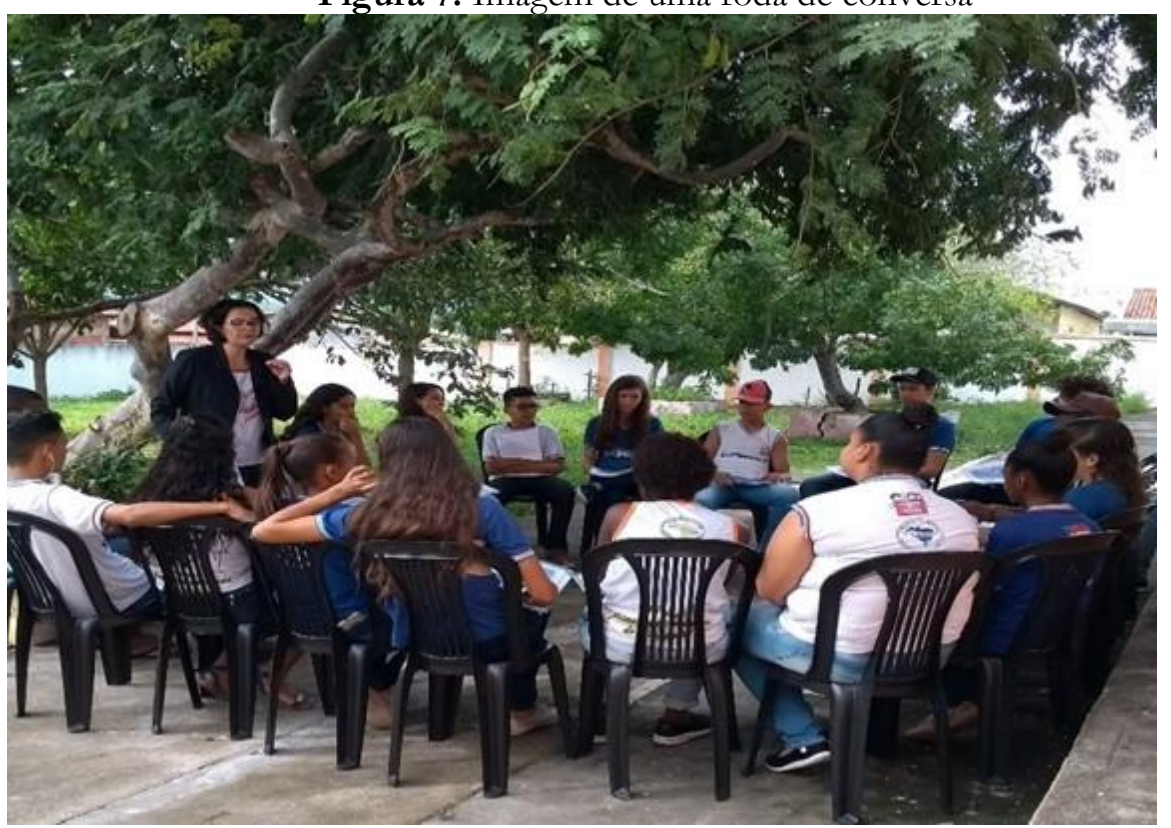

Fonte: Acervo da pesquisadora.

É interessante registrar que muitas dessas aulas, na qual era necessária à (re)leitura de trechos do romance foram elogiadas pelos alunos, pois eles eram convidados a sair do espaço fechado da sala de aula e correspondiam com empolgação. Então, o fugir da rotina e do espaço físico da sala de aula pode favorecer aulas com mais entusiasmo e, consequentemente, produtivas.

Na concretização da intervenção, houve aceitação do material didático preparado para a leitura e discussão da obra. Inclusive as atividades foram elogiadas pelos alunos, por apresentar uma abordagem diferenciada e propostas singulares, portanto o módulo didático foi aprovado pelo corpo discente envolvido no processo.

As aulas "ganharam vida" no decorrer na proposta de intervenção. As atividades lúdicas, a exibição de filmes, vídeos e canções, as leituras de imagem e de poemas e as rodas de conversa tornaram as aulas mais movimentadas. Os aspectos estruturais da língua costumam consumir muito tempo das aulas de Língua Portuguesa, as quais constituemse de rotina não atrativas para o aluno, tais rotinas foram quebradas durante a intervenção e as aulas se tornaram mais dinâmicas e proveitosas. Isso porque os aspectos estruturais da língua foram trabalhados por outro ângulo, na perspectiva da compreensão da funcionalidade e do uso dos recursos linguístico-gramaticais dentro dos textos lidos e discutidos e não pela via da metalinguagem.

Não houve muitos problemas com falta de participação, ociosidade ou indisciplina. De modo geral, os alunos se envolveram nas discussões e nas atividades propostas, pois tinham interesse, atenção e cuidado ao executá-las. De uma turma de dezoito alunos, dois precisaram de incentivo extra ou de alguma cobrança para terminar 
a leitura do romance e, aproximadamente, cinco estudantes necessitaram de mais estímulo para a produção das fanfics.

Houve também um estreitamento de laços afetivos em relação à turma, visto que um dos módulos tratou das relações interpessoais. As rodas de conversa proporcionaram momentos de partilha de experiência, possibilitaram aos alunos que compartilhassem algumas de suas histórias, memórias e de suas opiniões. Houve ainda uma excursão para Monte Santo, cidade onde vive a autora do romance, na intenção de promover um encontro entre autor e leitor. Tudo isso contribuiu para a interação da turma e os alunos ficaram mais unidos.

A reação diante dos textos literários trabalhados foi positiva. Geralmente, alguns alunos ao lerem um texto ficam limitados à superficialidade. Ao serem desafiados com as questões propostas na roda de conversa, eles conseguiam preencher as lacunas do texto e fazer uma reflexão coerente percebendo o elo existente entre o texto do romance e a realidade vivenciada. As discussões de trechos do romance (com analogia a fatos do cotidiano) contribuíram para um aprofundamento das questões identitárias e das relações humanas e serviram para alargar a percepção de mundo dos estudantes.

Embora os diálogos intertextuais entre as obras $A$ menina que cavava com a caneta $\mathrm{e}$ Capitães da Areia tenham se constituído de forma fragilizada, necessitando ainda de uma atenção, de modo geral, é pertinente classificar o projeto de leitura como uma experiência exitosa. A realização da intervenção foi um exercício da competência comunicativa a partir do letramento literário. Os estudantes se envolveram com o texto literário, demonstraram desde o primeiro capítulo interesse pela leitura, faziam parte das discussões dos capítulos nas rodas de conversa, das quais foram produtivas e serviram para evidenciar, de fato, que os alunos fizeram a leitura do romance. Podemos afirmar que a turma está superando as expectativas no desenvolvimento das atividades e o objetivo de ampliar a competência leitora dos estudantes foi atingido.

\section{PALAVRAS FINAIS}

Ainda que a execução desta proposta de intervenção não tenha sido finalizada, podemos parcialmente, afirmar que práticas inovadoras de leitura do texto literário em sala de aula podem ser transformadas e transformar professores e alunos. Promover o letramento literário impõe à escola uma postura coerente com os objetivos que almeja em relação às práticas de leitura.

Nessa direção, é vital que haja promoção de um ambiente favorável para a exploração das potencialidades do texto e criação de condições para o encontro entre aluno e obra literária, permitindo que o estudante compreenda a magia da obra e seus múltiplos significados. Esse caminho pode ser feito com práticas dinâmicas de leitura literária, na tentativa de promover momentos de discussão, interação e aprendizado. É possível dizer que as propostas apresentadas aqui apontem caminhos para que o texto literário tenha um lugar especial na escola, a fim de que a literatura cumpra seu papel de contribuir para a formação de cidadãos críticos (e humanizados) e o letramento literário, de fato, se concretize. 


\section{REFERÊNCIAS}

ANTUNES, Irandé. Aula de Português: encontro \& interação. São Paulo: Parábola Editorial, 2003.

BAKHTIN, Mikhail. Os gêneros do Discurso. In: Estética da criação verbal. São Paulo: Martins Fontes, 1997.

BAKHTIN, Mikhail. O romance de educação na História do Realismo. In: Estética da criação verbal. São Paulo: Martins Fontes, 1997 [1952].

BONINI, Adair. A noção de seqüência textual na análise pragmático-textual de JeanMichel Adam. In: MEURER, J. L.; BONINI, Adair; MOTTA-ROTH, Désirée. (orgs.). In: Gêneros: teorias, métodos, debates. São Paulo: Parábola, 2005.

BRASIL. Ministério da Educação. Parâmetros Curriculares Nacionais: terceiro e quarto ciclos do Ensino Fundamental Lingua Portuguesa. Brasília, 1998.

CÂNDIDO, Antônio. O direito à literatura. In: Vários escritos. Rio de Janeiro: Ouro sobre Azul, 2011.

CORREIA, Sarah. A menina que cavava com a caneta. 5. ed. São Paulo: Lura Editorial, 2016.

COSSON. Rildo. Letramento literário: teoria e prática. 2. ed. São Paulo: Contexto, 2014.

DOLZ, Joaquim; SCHNEUWLY, B; e colaboradores. Gêneros orais e escritos na escola. Tradução e organização de Roxane Rojo e Glaís Sales Cordeiro. Campinas/ SP: Mercado de Letras, 2004.

FAILLA, Zoara (Org.). Retratos de Leitura no Brasil 4. Rio de Janeiro: Sextante, 2016.

FERRAREZI, Celso; CARVALHO, Robson S. Exposição ao material de leitura. In: De alunos a leitores: o ensino da leitura na educação básica. São Paulo: Parábola Editorial, 2017.

JOUVE, Vincent. A leitura. São Paulo: UNESP, 2002.

KLEIMAN, Ângela. Preciso "ensinar" o letramento? Não basta ensinar a ler e a escrever? Cefiel/IEL/Unicamp: 2006.

LAJOLO. Marisa. Do mundo da leitura para a leitura de mundo. São Paulo: Ática. 1999.

MARCUSCHI, Luiz Antônio. Gêneros textuais no ensino da língua. In: Produção textual, análise de gêneros e compreensão. São Paulo: Parábola Editorial, 2008.

ROJO, Roxane. Multiletramentos na escola. São Paulo: Parábola Editorial, 2012.

SCHÜLER, Donaldo. Teoria do Romance. São Paulo: Ática, 1989.

SILVA. Ezequiel Theodoro da. Leitura na escola e na biblioteca. Campinas, SP: Papirus, 1986.

SOARES. Magda. Letramento: um tema em três gêneros. 2. ed. Belo Horizonte: Autêntica, 2002. 
SOLÉ, Isabel. Estratégias de leitura. 6. ed. Porto Alegre: ArtMed, 1998.

STREET, Brian. Letramentos sociais: abordagens críticas do letramento no desenvolvimento, na etnografia e na educação. Trad. Marcos Bagno. São Paulo: Parábola Editorial, 2014.

YUNES, Eliana. Pensar a Leitura: complexidades. Rio de Janeira: E. PUC-Rio; São Paulo: Loyola, 2002.

ZILBERMAN, Regina. A leitura e o ensino da literatura. 2. ed. São Paulo: Contexto

Recebido em: 13/05/2018

Aprovado em: 16/08/2018

Publicado em: 31/12/2018 